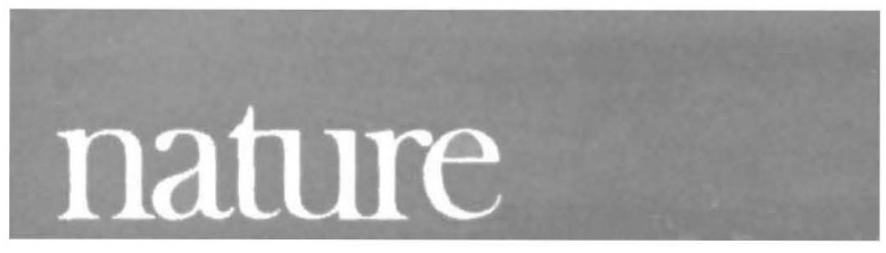

Volume 249

June 7, 1974

\section{Problem-solving PhDs}

Although the disillusionment of industry with at least some aspects of the present $\mathrm{PhD}$ system has been highlighted this year by the report of the House of Commons Expenditure Committee on postgraduate education, declarations on the need for change were made by academics and industrialists on the Swann Committee as long ago as 1968. That committee looked into the whole question of the flow of qualified personnel into employment and roundly stated that the universities should "experiment boldly" with the PhD and with the regulations governing its award.

Academics protest, quite rightly, that the $\mathrm{PhD}$ is not only a training in methods of research but also a means of preserving the continuity of university researchthe aim of which is to generate new knowledge. That said, the question is whether too many 'conventional' $\mathrm{PhDs}$ are being produced. The fact is that of some 4,600 scientists graduating with higher degrees in 1971, some 1,200 took up employment outside teaching and lecturing, and although many of these had master's degrees a substantial number had doctorates. It seems logical therefore that some $\mathrm{PhD}$ students should carry out postgraduate work that will fit them for their eventual career in industry.

Changes along these lines have already been made by the Science Research Council (SRC). First, it has been running the so-called CASE scheme (Co-operative Awards in Science and Engineering). In 1972, 191 of these awards were made, out of a total of 2,220 new SRC research studentships. The SRC also offers postgraduate studentships to people who wish to do a postgraduate course after a spell in, for example, industry or teaching; 313 of these were taken up in 1972, for both research leading to a $\mathrm{PhD}$ and for advanced courses.

Like all collaborative schemes CASE has not been without its problems. The scheme requires joint supervision of the student by a member of the staff of the university concerned and a person from the collaborating institution, which following a relaxation in the rules may be a body like a hospital board or a local authority rather than specifically an industrial company. Trouble has arisen because the projects to be tackled have in some cases been badly or vaguely specified and often because of a lack of mutual understanding between the industrialist and the academic.

Yet another kind of doctorate that has emerged in the past few years is the interdisciplinary $\mathrm{PhD}$. The idea arose from the discussions following the publication of the Swann report and involves a graduate, often, though not necessarily, a scientist, getting to grips with a real industrial problem which calls for an appreciation of economics, industrial relations and the like. The SRC and the Social Science Research Council jointly fund almost 100 interdisciplinary research studentships, about 30 of which are held at the University of Aston.

The University of Aston is also in the throes of preparing for the advent of "total technology" $\mathrm{PhD}$ courses. These are specifically for engineers and have many of the characteristics of the interdisciplinary higher degree scheme but with more formal course work. What the research student is required to do is to solve real engineering problems in a real company. The University of Aston is well placed to take advantage of this because it already has the central organisation that is required if projects for students are to be thought out properly before the student arrives. The SRC awarded the first six total technology studentships last year.

That is all very well, but what scope is there for the pure scientist who wants to do a 'nonconventional' $\mathrm{PhD}$ yet wants something different from the CASE scheme. One answer is that there should be more scope for research done in an industrial environment to form the basis of a university $\mathrm{PhD}$ thesis. Unfortunately some universities take the view that they are not in the business of externally examining for a PhD. They might do well to re-examine such an isolationist attitude.

Some may say that to extend the PhD concept too much is to reduce the degree to a certificate of ability to solve problems. But does this matter? Provided that those who are really cut out to do research in the true sense of the word still have a reasonable chance to do it the appearance of more doctors of problem solving (which is all some 'conventional' PhDs are at the moment anyway) seems to be much more of a benefit than a threat.

\section{0 years ago}

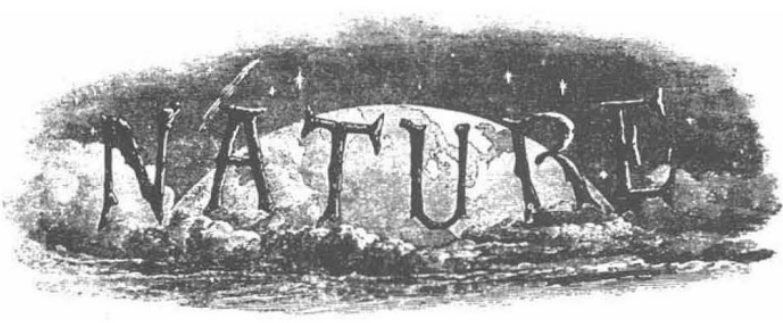

AN extract from a letter by Mr. Dunn, the geologist, now on a special exploring expedition to the Transvaal, published in the Cape Argus of May 5, gives a description of a thunder and hailstorm which he experienced at Pietermaritzburg, on April 17 :" Hail-stones, liberally mingled with great masses of ice of very irregular forms, poured down with great violence. The hailstones were seldom less than $I$ in. in diameter; the average was from $\mathrm{I}$ lin. to $2 \mathrm{in}$. in diameter. These were of very regular spherical form, and consisted of a nucleus of white snow, with an envelope of hard transparent ice. Sometimes they presented, when broken through, a concentric arrangement of zones, alternately white and opaque and transparent. The irregular masses were formed of a nucleus generally longer in one direction than the others, from $2 \mathrm{in}$. to $4 \mathrm{in}$. in diameter; projecting all over were stalactites, each one about the thickness of a little finger, and presenting, when broken across, an agate, like structure, as though segregation had built them up. Of these masses I weighed a few with the following results:-Three weighed over $8 \mathrm{oz}$., two over $6 \mathrm{oz}$., and one over $4 \mathrm{oz}$. The mischief done will nct be covered by $2,000 \%$. or anything like that sum."

From Nature, 10, 115, June 11, 1874. 